\title{
Solidarity and The Politics of Redress: Structural Injustice, History and Counter-Finalities
}

\author{
David Owen ${ }^{1}$ (D)
}

Accepted: 6 October 2021 / Published online: 10 December 2021

(c) The Author(s) 2021

\begin{abstract}
This paper examines Nuti's accounts of structural injustice and historical injustice in the light of a political dilemma that confronted Young's work on structure injustice. The dilemma emerges from a paradox that can be stated simply: justly addressing structural injustice would require that those subject to structural injustice enjoy the kind of privileged position of decision-making power that their being subject to structural injustice denies them. The dilemma thus concerns how to justly address structural injustice. I argue that Nuti's account is currently unable to provide an adequate theorization of how to address this dilemma because it lacks an account of political solidarity, but also that her account provides important resources for dissolving a dispute between two competing theories of solidarity in a way that facilitates the articulation of an account of political solidarity that is adequate to addressing the political dilemma.
\end{abstract}

Keywords Structural injustice · Historical injustice · Alessia Nuti · Iris Marion Young • Solidarity $\cdot$ Redress

The development of the concept of structural injustice to explore historical injustice represents an important re-focusing of the nature and scope of debates in this area. The recent work of Catherine Lu and now of Alasia Nuti have opened up and powerfully extended the innovative work of Iris Marion Young in ways that are undoubtedly productive for conceptualising historical injustice and thinking about how to respond to it. In this response to Nuti's argument, I want to explore the extent to which she offers resources to address a political dilemma that I have argued confronted Young's own reflections on structural injustice and what the implications of this dilemma may imply for her own argument. The dilemma emerges from a paradox that can be stated simply: justly addressing structural injustice would require that those subject to structural injustice enjoy the kind of privileged position of decision-making power that their being subject to structural injustice denies them. The dilemma thus concerns how to justly address structural injustice.

I'll begin by reconstructing the concept of structural injustice and outlining the sources of the dilemma in question by attending to Young's use of Sartre's concept of

David Owen

dowen@soton.ac.uk

1 Department of Politics and International Relations, University of Southampton, Southampton, UK 
counter-finalities. I'll then turn to Nuti's own reflections, first, on structural injustice and, second, on the development of structural injustice arguments to the context of historical injustice in order to address the strengths and limitations of her own arguments in relation to the political dilemma. I'll conclude by arguing that what is required to complete Nuti's arguments is an account of solidarity, and I will attempt to lay out the form of such an account.

\section{Structural Injustice, Counter-Finalities and the Political Dilemma}

Within contemporary analytic political philosophy, much of the basic conceptual work for the formation of the concept of structural injustice is done by Rawls in drawing attention to the phenomenon of background injustice and motivating the claim that the basic structure should be seen as the primary subject of justice. Thus, in 'The Basic Structure as Subject', he remarks:

Suppose we begin with the initially attractive idea that social circumstances and people's relationships to one another should develop over time in accordance with free agreements fairly arrived at and fully honored. Straightaway we need an account of when agreements are free and the social circumstances under which they are reached fair. In addition, while these conditions may be fair at an earlier time, the accumulated results of many separate and ostensibly fair agreements, together with social trends and historical contingencies, are likely in the course of time to alter citizens' relationships and opportunities so that the conditions for free and fair agreements no longer hold. The role of institutions that belong to the basic structure is to secure just background conditions against which the actions of individuals and associations take place. (Rawls, 1993: 265-6).

It is important to be clear here that Rawls' point is that background justice can be undermined even if all participants fully comply with the norms of fairness internal to their local interactions. He writes:

Fair background conditions may exist at one time and be gradually undermined even though no one acts unfairly when their conduct is judged by the rules that apply to transactions within the appropriately circumscribed local situation. ... We might say: in this case the invisible hand guides things in the wrong direction. (Rawls, 1993: 267).

In articulating the idea of background injustice and its relationship to the basic structure, Rawls' has provided almost, but not quite, all the materials needed for the concept of structural injustice. What is missing? Young defines structural injustice as follows:

Structural injustice exists when the combined operation of actions in institutions put large categories of persons under a systematic threat of domination or deprivation of the means to develop and exercise their capacities, at the same time as they enable others to dominate or give them access to an abundance of resources. Structural injustice is a kind of moral wrong distinct from the wrongful action of an individual agent or the wilfully repressive policies of a state. Structural injustice occurs as a consequence of many individuals and institutions acting in pursuit of their particular goals and interests, within given institutional rules and accepted norms. (2007: 170). 
The key element in terms of the distinction from the general concept of background injustice is the focus on 'categories of persons', both those 'under a systematic threat of domination or deprivation' and those enabled to dominate and access abundant resources. What distinguishes the concept of structural injustice from that of background injustice is that structural injustice refers to a relatively durable patterned form of background injustice. The conceptual move from the general concept of background injustice to the specific concept of structural injustice is thus predicated on the introduction of the sociological concept of social structure. Young specifies this concept in terms of four features:

a) A social structure is a multidimensional space (Blau) or field (Bourdieu) composed of positions and their relationships across which a given population is distributed.

b) Social structures exist only in the actions and interactions of persons; as processes, not states, composed of the recursive employment of rules and resources (what Giddens call structuration).

c) Social structures inherit the outcomes of past actions and interactions in the form of determinate material and ideational effects on the physical and cultural contexts (the practico-inert in Sartre's terms) within which contemporary action and interaction is situated and which condition their possibilities for action in various ways.

d) Structured social action and interaction often have consequences that extend beyond the intentions of the individual and collective actors involved and may produce effects that are counter to the best intentions of these actors (what Sartre refers to as counterfinalities). (Young 2007: 170)

Structural injustice thus refers to relatively durable patterns of positional difference that are reproduced through social-historical processes and which shape relations of domination and disadvantage between social groups that have no necessary connection to the avowed intentions of actors. The point of introducing the concept of social structure in relation to the Rawlsian focus on basic structure and hence giving articulation to the idea of structural injustice is that this makes necessary and desirable a widening of the focus of justice from Rawls' emphasis on distributions. As Young comments:

While patterns of the distribution of recources, opportunities, and income are very important issues of justice, theoretical focus on them tends to deflect attention from important aspects of structural processes in at least two ways. First, focus on distributions pays too little attention to the processes that produce the distributions. Second, focus on distributions of benefits and burdens obscures important aspects of structural processes that do not fit well under a distributive paradigm. (Young 2006: 91).

Such 'important aspects' include 'the social division of labor, structures of decisionmaking power, and processes that normalize behavior and attributes of persons' (Young 2006: 91).

I have spent some time reconstructing the emergence of the concept of structural injustice and the centrality to this concept of the theorization of social structure. The reason for doing so is twofold. First, because it is taking social structure seriously and thereby widening the focus of justice in the way that Young does that generates the political dilemma - and it is this point on which I want to focus now. Second, because grasping this point is central to understanding Nuti's work as I will demonstrate in the next two sections.

The political dilemma arises in relation to the topic of responsiveness to structural injustice, of how we should address structural injustice, and it is one that follows directly from 
Young's characterization of social structure and acknowledgment of the phenomenon that Sartre termed 'counter-finalities':

The actions and interactions which take place among persons differently situated in social structures using rules and resources do not take place only on the basis of past actions whose collective effects mark the physical conditions of action. They also often have future effects beyond the immediate purposes and intentions of the actors. Structured social action and interaction often have collective results that no one intends and which may even be counter to the best intentions of the actors. Sartre calls such effects counter-finalities. (Young 2007: 170).

The issue is that this point about social structures necessarily also encompasses efforts to transform them in order to address the injustice which the current structure (re)produces. The best-intentioned efforts at reforms directed to addressing structural injustice not only may produce effects that run entirely counter to those intentions; they are, given the characterization of social structures, likely to do so.

This is not an argument for fatalism. Acknowledging that changing social structures is likely to have unintended effects that may be positive, negative or neutral with respect to the intended goal does not mean that there is no reason to pursue reform. It does, however, immediately raise a further issue of justice which Young's own reflections on structural injustice do not fully register, namely, the question of how decision-making power concerning how to address the structural injustice in question should be distributed given that distinct social groups will be differentially vulnerable to unintended consequences of structural changes. However, the problem goes deeper than this because this predicament is further complicated by the fact that social structures - for example, social structures of race and of gender - intersect and interact such that seeking to address one form of structural injustice is liable to have effects on other entangled social structures. (It also, thereby, raises the question of how agents of justice are to judge whether the outcomes of their actions advance overall justice as opposed to justice in a specific domain such as gender justice).

One line of response to this theoretical dilemma that I have advanced elsewhere (Owen 2014) draws on another feature of Young's work to argue that whereas, on the one hand, responsibility for change should be distributed on the basis of the parameters such as the degree of causal role in reproducing structural injustice, advantage accrued through structural injustice, and power to transform unjust structures; on the other hand, decision-making power for (the direction of) change should be arranged in terms of degree of vulnerability to unintended effects of changes, that is, decision-making power should be biased towards those who are most subject to domination and disadvantage. This, however, generates a paradox: justly addressing the structural injustice to which a group is subject would require that they enjoy the kind of privileged position in decision-making power which their subjection to structural injustice denies them - and hence the political dilemma of how to address this paradox in practice. The question of how to negotiate this dilemma is perhaps the central political question that issues from acknowledgment of our exposure to counter-finalities in addressing structural injustice. It is with this topic to the fore that I now turn to Nuti's reflections on structural injustice, before turning in the following section to her work on historical injustice as structural injustice. 


\section{Nuti on Structural Injustice}

The approach Nuti takes to structural injustice in Injustice and the Reproduction of History draws on her earlier work on the subject, including her article on intra-EU temporary labour migration (TLM). In this section, I want to draw attention to three features of her approach in respect of this contemporary example of structural injustice:

1) The conceptualisation and individuation of structural injustices,

2) The attention to the interaction of forms of structural injustice,

3) The approach to redressing structural injustice.

I do so in order to demonstrate that Nuti's analysis implicitly recognizes the political dilemma and the need to address it, but also lacks the resources to articulate and engage it.

The choice of intra-EU TLM is apposite for a focus on structural injustice because it allows Nuti to bracket a range of unjust acts that are widely prevalent in state-based TLM programmes in order to focus on a context in which, at least formally, all actors enjoy the same EU citizenship rights (most obviously rights of free movement), but is also characterised by the general reciprocal commitment of Member States to equal treatment and nondiscrimination in matters of employment. This allows her to focus on 'the entanglement and accumulation of multiple processes that underlay temporary migrants' condition of vulnerability' (2018: 209). Nuti focuses on both formal and informal processes. Her example of a formal process is the case of 'posted workers' in which migrant EU citizen-workers are to be paid at the local rate but where their social payments are delivered at the home state rate and resident state trade unions are prevented from collectively bargaining on their behalf. Informal processes include the dependence of migrant EU worker-citizens on social networks and recruitment agencies that are likely to steer migrants to particular sectors of "low-skilled" and precarious employment in ways that do not match their qualifications or abilities, and that draw on stereotypes concerning workers from a given sending state. This is a process that is itself structured by the role of recruitment agencies within flexible labour markets (Nuti, 2018: 210-11). Why is this an instance of structural injustice? Nuti's argument is that the condition of such intra-EU TLMs is 'a position within social and transnational structural processes that puts those who occupy it under a systematic condition of vulnerability' that is reproduced through these structural processes which, at the same time, place others in positions of privilege (2018: 212).

We can begin our critical analysis by taking up a point concerning the individuation of structural injustices. Nuti identifies the disadvantaged as intra-EU TLMs but the advantaged as groups 'such as middle- or high-skilled native workers and migrants coming from other member states that are perceived to have a more international or prestigious level of education and professional experience' (2018: 212). This rather muddies the water. Consider the possible options that may be in play:

a) Structures of positional difference within the class of intra-EU TLMs between TLMs from the Eastern European A8 (e.g., Poland) \& A2 (e.g., Romania) states and those from 'old Europe' states (e.g., Spain)

b) Structures of positional difference between intra-EU TLMs and intra-EU permanent labour migrants (PLMs)

c) Structures of positional difference between intra-EU migrants (especially TLMs) and native workers 
d) Structures of positional difference between worker and professional classes.

Much of Nuti's empirical focus is on (a) and her reference to 'other member states' may also suggest that this is her target. But at the same time the argument is framed in terms of intra-EU TLM as a whole which suggests that (b) or (c) are the relevant contrasts. While her attention to the contrasting effects of intra-EU TLM for low-skilled native workers compared to medium/high skilled native workers suggests that (d) is the relevant structural injustice and processes associated with intra-EU TLM as simply one element in a wider set of processes that reproduce disadvantaged workers and privileged professionals on nationality-based as well as class-based grounds. The problem here concerns the individuation of structural injustices and that requires showing how the production of disadvantage for a given category of persons is causally related, systematically linked, to the production of privilege for another category of persons. But this is not something that Nuti supplies. It may be, of course, that Eastern European intra-EU TLMs are positioned at the intersection of more than one type of structural injustice - one perhaps focused on Eastern European migrants in the EU, another on EU citizen TLMs more generally, another on workers as a whole, etc. However, in the absence of the relevant causal analysis, this remains indeterminate. The sources of vulnerability to which Nuti draws attention may be tied to distinct structural processes which differentiate different categories of persons in terms of disadvantage and privilege with Eastern European TLMs falling within the disadvantaged category in each of these processes. This is a problem, we might suppose, because in the absence of the kind of causal analysis that individuates structural injustices, how are we effectively to address them or to determine who is entitled to decision-making power?

It seems to me that Nuti's account is limited in terms of its ability to individuate 'temporary labour migration within the EU' as a distinct structural injustice. However, it is a strength of her account that she is attentive to the interaction of the structural processes within which Eastern European TLMs are situated with other structural processes that reproduces positional difference through racialised and gendered categories of persons. So, for example, Nuti's account is sensitive to the ways in the equation of the racialised 'whiteness' of Eastern European TLMs with characteristics of hard work, reliability and obedience serves to reproduce the disadvantaging of non-White non-EU TLMs. It is also attentive to the ways in EU care chains in which Eastern European women who migrate for great freedom from the gendered structures of culturally conservative home states (e.g., Poland) find themselves employed in care roles in the receiving state, while wider female family members take up the child-care roles in the home state, thereby reproducing gender structures of disadvantage and privilege in both home and receiving states.

The salience of Nuti's conceptualisation of structural injustice and the issues of individuation and of interaction come together in the context of considering how to address structural injustice. Thus Nuti points to an ever expanding range of changes that would be 'profound, long-term, and difficult to bring about' and require 'systematic interventions at multiple levels' involving multiple state and non-state agents (2018: 2020). One explanation for the sheer range of changes that she sees as necessary is that she has not adequately individuated the specific structural injustice she purports to be addressing. While that may be true, there is a more charitable reading of her argument that sees it as recognizing that the structural injustice(s) to which Eastern Europe TLMs are subject intersect with injustices to which different ranges of persons are subject and that securing justice for the former group has to be addressed in ways that also secure justice for the wider groups. 
Significantly for our concerns, Nuti recognizes that EU TLMs are not just an important epistemic resource in addressing such changes but should also count as agents of change (2018: 2020-21). Given the dispersed character of EU TLMs and the salience of their immediate individual interests in contexts of precarity, she argues that

other collective agents with higher capacities for collective action, such as migrant nongovernmental organisations, migrant worker organisations, and trade unions, should attempt to involve [EU TLM] migrants in collective actions, and that doing so will require them to engage in new strategies of mobilization. (2018: 2020).

Indeed, she goes further and argues that, ideally, such strategies should expand to include all who are made vulnerable by any of the elements that comprise the EU TLM regime:

Joint action must be inclusive, targeting those common structures that unjustly put all parties in a situation of vulnerability while also recognizing that different parties may have different interests and occupy different interests within such structures. (2018: 2021).

This point is important for two reasons. The first is that it verges on recognition of the political dilemma and the significance of securing voice for those subject to injustice in giving direction to change. The second is that it compensates (at least partly) for her failure to individuate structural injustices, because it recognizes that the class of those who are potentially vulnerable to counter-finalities in any transformation of social structures are not simply those who are subject to a specific individuated structural injustice but, given the intersection of what may be different structural processes, all those who stand in general positions of vulnerability (i.e., those who are subject to overall positions of being dominated and disadvantaged). ${ }^{1}$ Addressing EU TLMs alone may introduce changes that are positive for this group but that are negative for other vulnerable workers or for (typically female) carers on whom such changes impact. But pointing to the need for inclusive joint action is not yet to theorise the political dilemma to which I have drawn attention. Nuti's argument verges on recognition of the problem posed by the paradox I have sketched but ultimately stops short and hence is not capable of addressing the dilemma that it generates. This requires, I will argue, more than an appeal to 'collective agents with higher capacities for collective action, such as migrant nongovernmental organisations, migrant worker organisations, and trade unions ... to involve [EU TLM] migrants in collective actions', rather addressing the political dilemma requires an account of solidarity. However, before turning to this account, I want to consider Nuti's recent work on historical structural injustice to see if this offers more resources for addressing the political dilemma.

\section{Nuti on Historical Injustice}

The central claim advanced in Nuti's sophisticated account of historical injustice in Injustice and the Reproduction of History is that rather 'than being conceived as merely enduring, historical injustices should be regarded as historical-structural injustices ... that are newly reproduced over time.' (2019: 44) Whether or not all historical injustices can be

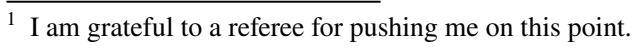


adequately captured by this framework of de-temporalising injustice, it at least captures an important class of such injustices which Nuti defines in terms of 'unjust social-structural processes enabling asymmetries between different positioned persons, which started in the past and are reproduced in a different fashion, even if the original form of injustice may appear to have ended.' (2019: 44, cf. 60) Using this schema, Nuti initially distinguishes between two types of structural injustice and, relatedly, two type of structural groups (where structural groups are specified by their relational character and the ascriptive constitution of membership): historical and non-historical. The latter refers the classic case introduced by Young's initial account of structural injustice and would include the case of EU TLMs we have just considered. The former refers to those picked out by Nuti's definition and would include indigenous peoples in settler colonial states, African Americans and women, all of whom have been subject to direct forms of injustice such as dispossession, slavery and exclusion from political rights that are now decried by liberal states but those position of disadvantage and domination relative to privileged groups is reproduced through other means. (Nuti argues for a spectrum of groups across this distinction and introduces a third type: historical groups with structural dynamics - but I will leave this aside here.)

This, then, becomes central to Nuti's characterisation of 'women' as a collective category. Acknowledging that feminism as movement requires a collective identification of women around which it mobilises which Nuti refers to as 'women*', Nuti proposes an account of women* as an historical-structural group in which they are defined as:

a particular category that is rooted in past legally enforced discrimination and exclusion, and whereby society still groups persons so as to differently distribute expectations, norms and social roles. By being recognized as women, persons are located into a particular position of disadvantage within certain social structures and relation to 'men', who, instead, are located in a position of advantage. In virtue of being structurally positioned as women, persons can potentially encounter a set of constraints, expectations, stereotypes and abuses which in a specific context is associated with the position women*. (Nuti 2019: 98)

There is an obvious circularity in this account of women* but it is not a vicious circularity. Rather it is a recognition that the category of women* and historical structural injustice are co-determining in relation to feminism as a social and political movement. Importantly, Nuti's account also aligns with intersectionality in acknowledging that women* may be differently situated in relation to other historical (e.g., colonialism) and non-historical (e.g., EU TLM regime) structures that shape and inflect the set of constraints, expectations, etc., that they potentially encounter. This is a point she illustrates by considering how a structural approach enables understanding of how the forms of violence against women are shaped by intersections with other forms of structural injustice, for example, how the forms of violence against indigenous women are shaped by structures arising from unjust colonial histories (2019: 115-117). Through consideration of a range of persisting injustices against women, Nuti presents a compelling case for her claim that roots of these enduring injustices lie 'in the structural interplay between (unjust) history and (present) injustice.' (2019: 128). How, though, are these enduring injustices to be addressed?

Here Nuti makes two arguments. The first is that responses to historical-structural injustices need to be highly sensitive to context. They need to acknowledge the specific historical forms in which historical-structural injustices manifest themselves in different societies and which differentially shape the operation of category 'women*' and the particular images, expectations, norms and constraints within those societies. The second is that 
where the origin of the historical-structural injustice can be identified with specific discrete historical injustices (e.g., slavery, colonialism, exclusion from political membership) whose unjust effects are reproduced through other means, the contrastive group who enjoy advantages and privileges on the basis of such historical-structural processes can be seen as accumulating a 'structural debt' that they have a responsibility to discharge through reparative mechanisms. In working out how the politics of redress should be engaged, Nuti argues for a position which is consonant with my own earlier proposal (Owen 2014). Responsibility for change lies with those who are advantaged by the existing unjust structure: 'Those who are privileged vis-à-vis certain structures should be politically responsible for their eradication,' (Nuti 2019: 190)—but decision-making for the direction of change should privilege the voice of those disadvantaged by this structure through a participatory process: 'claimants ... need to be in the vanguard of the entire process' (Nuti 2019: 169). It is a strength of her account that Nuti goes further than I did in stressing the need for a selfconsciously intersectional approach to such participatory processes of redress.

Yet although Nuti here introduces the issue of solidarity between members of the oppressed group as a way of thinking about the responsibility of the disadvantaged within the structural injustice (2019: 192), her account stops short of recognizing the need to develop an account of solidarity or articulating the wider significance of theorizing solidarity for addressing structural injustice and the political dilemma with which it confronts us, especially in contexts of interacting structural injustices and intersectional forms of disadvantage. However, the participatory approach to addressing historical and non-historical forms of structural injustice that she proposes requires such an account if it is to formulate a politics of redress that is capable of addressing the political dilemma. In the next section I will attempt to provide such an account and I will suggest that Nuti's own reflections on structural injustice and intersectionality provide some resources for working out such an account and for helping to resolve a contemporary debate concerning the normative idea of solidarity.

\section{Solidarity and the Political Dilemma}

To work out how theorizing solidarity enables us to address the political dilemma sketched at the start of this essay, we need to begin by noting two competing, and prima facie incompatible, joint action accounts of political solidarity construed as 'a commitment to a common cause to end injustice or oppression.' (Scholz 2015: 733, see also Scholz 2008). The first account conceives of solidarity as a symmetrical relationship; the second as an asymmetrical relationship.

The first account is offered by Sangiovanni (2015) and it can be specified as follows:

I act in solidarity with you when:

1. You and I each (a) share a normatively justified goal (b) to overcome some significant injustice;

2. You and I each individually recognize our responsibilities to do our part in achieving the shared goal in ways that mesh;

3. You and I are each individually committed (a) to the realisation of the shared goal and (b) to not bypassing each other's will in the achievement of the goal;

4. You and I acknowledge our obligation (a) to incur significant costs to realise our goal if necessary; and (b) to share one another's fates in ways relevant to the shared goal. 
5. Facts 1.-4. need not be common knowledge.

This view of political solidarity as shared action grounded on a shared goal can be differentiated from another shared action conception advanced by Kolers who argues for a conception of solidarity as 'reason-driven action on other's terms.' (2016: 57, see also Scholz 2015: 273) It is a notable feature of Kolers' account that he offers a direct challenge to Sangiovanni's view:

Sangiovanni assumes that solidarity is a symmetric relation, such that $\mathrm{S}$ is in solidarity with $\mathrm{G}$ iff $\mathrm{G}$ is in solidarity with $\mathrm{S}$. But solidarity is not a symmetric relation; it is deferential. ... Solidarity is therefore asymmetric ... (Kolers 2016: 61).

For Sangiovanni, solidarity is a symmetric relation because those in a relationship of solidarity have a shared goal and are committed to '(a) to the realisation of the shared goal and (b) to not bypassing each other's will in the achievement of the goal'. By contrast, Kolers argues that solidarity is an asymmetric relation in which S defers to G's specification of the goal and $\mathrm{S}$ is committed to not bypassing G's will. How are we to approach this apparently fundamental disagreement about the concept of solidarity?

My proposal is one of dissolving, rather than resolving, the appearance of disagreement by noting that each account specifies its conception of solidarity in terms that privilege a particular set of 'core' cases. In the case of Sangiovanni, the cases privileged concern the workers movement in Europe that saw the term 'solidarity' gain widespread traction in political discourse. By contrast, Kolers takes as core examples the support of privileged agents for social movements of the dominated and disadvantaged such as the Civil Right Movement or, in more contemporary context, Indigenous Rights movements and movements such as Black Lives Matter. Thus, Sangiovanni offers a conceptualisation of solidarity that addresses relations between members of a structural group, hence the symmetrical character of his account, whereas Kolers offers a conceptualisation that address relations between members of a group who stand in relations of privilege to the structurally disadvantaged group and the members of the structurally disadvantaged group, hence the asymmetrical character of his account. Rather than seeing one of these as basic to the concept of solidarity in a way that excludes the other, I propose that we are guided by our ordinary use of the word 'solidarity' to describe both types of relationship and that we see each view as picking out a distinct kind of solidarity: Sangiovanni's account captures the normative character of solidarity between members of an oppressed or disadvantaged group: in-group solidarity, while Koler's account addresses the normative character of solidarity with disadvantaged groups by those who occupy privileged positions as a result of structural injustice: out-group solidarity. ${ }^{2}$ The distinction between, and potentially dynamic relations of, these two types of solidarity is, I'll now argue, central to addressing the political dilemma.

Recall that the dilemma is that that justly addressing structural injustice would require that those subject to structural injustice enjoy the kind of privileged position of decisionmaking power that their being subject to structural injustice denies them. There are two key elements to this dilemma. First, the importance of those subject to structural injustice being able collectively to work out what directions of change they would endorse and mobilise their collective power towards this end. Second, the importance of those privileged supporting the disadvantaged group in acquiring sufficient power to play a primary

${ }^{2}$ I am grateful to a referee for suggesting the use of in-group/out-group solidarity as appropriate terms. 
role in directing change. Put simply, what is required to address the political dilemma is the combination of in-group solidarity and out-group solidarity. While true, there are two respects in which this point is made too simply - and seeing how will help us see how the relationship of these two forms of solidarity is integral to the politics of redress.

The first is that taking these accounts of solidarity as distinct and complementary draws attention to the importance of the realization of the capacity of disadvantaged group for setting and pursuing goals that are shared by members of the group (i.e., the need to establish relations of solidarity between members of the group and to build the organizational capacity for the group to articulate its goals). But building the in-group solidarity of the disadvantaged requires resources and commitment, and while the disadvantaged can perform this work autonomously, the burdens of doing so can be significantly reduced by out-group solidarity that takes the form of providing resources and support. Indeed, we might say that the first responsibility of out-group solidarity is to support the generation of in-group solidarity. This is implied by Kolers' asymmetric account since the deference of the out-group to the ends set by the in-group (as long as these ends are permissible by reasonable conceptions of justice) presupposes the capacity of the in-group to set ends that can reasonably claim to represent their structural group. Consider here Nuti's account of structural groups such as women*. She remarks:

My conception denies that the bonds of solidarity and affinity that those belonging to the same structural group may (or may not) develop and their (potential) feeling of having a shared identity should play a role in (1) defining criteria of membership in the structural group and (2) determining whether these groups suffer from injustices that are both historical and structural. That said, my account also acknowledges that other dimensions of membership in structural groups, such as how persons experience their belonging to such collectives, the value they place on their membership, and the networks they establish with those similarly positioned, become highly relevant when we consider the actions that should be taken to address the condition of injustice these structural groups suffer from. (2019: 183)

We can read the distinction being drawn here as echoing the Hegelian-Marxist distinction between a "group-in-itself" which refers to a collectivity of persons who are defined by occupying the same position in relation to a given social structure (e.g., women, the working class, etc.) and a "group-for-itself" which refers to that same group but now as conscious of their shared interests in overcoming the structures that sustain and reproduce their position of unjust disadvantage. As Nuti makes clear, her account of a structural group does not make any reference to 'their (potential) feeling of having a shared identity', it just specifies those who occupy a shared structural position. But, as she acknowledges, this can serve as the basis for 'other dimensions of membership' that emerge from 'how persons experience their belonging to such collectives, the value they place on their membership, and the networks they establish with those similarly positioned'. These 'other dimensions' pertain to the realization of in-group solidarity, that is, to becoming a "group-for-itself". The 'other dimensions', to which Nuti adverts, matter because the degree to which they are present or absent is salient to the ease of establishment of solidarity between members of the group and the building of their collective capacity for articulating how they conceive of the injustice to which they are subject and what is needed to overcome it. The solidarity of the privileged with the oppressed that will involve shared action that defers to this articulation of the goal requires that such solidarity takes the prior step of supporting the development of solidarity between the oppressed in order for them to be able to articulate their collective goal. Recall Nuti's discussion of the dispersed character of EU TLMs and 
the salience of their immediate individual interests in contexts of precarity in which she argues that

other collective agents with higher capacities for collective action, such as migrant nongovernmental organisations, migrant worker organisations, and trade unions, should attempt to involve [EU TLM] migrants in collective actions, and that doing so will require them to engage in new strategies of mobilization. (2018: 2020).

What I am suggesting is that a key role of these 'other collective agents' is not simply to involve EU TLM migrants in collective actions as Nuti supposed, but to provide the resources for EU TLM migrants to recognize and develop solidarity between themselves and the organisational capacity for articulating claims and goals. Although Nuti does not recognize this point in her discussion of EU TLM, we are now in a position to see that out-group solidarity with the disadvantaged group (here EU TLMs) may be important for enabling the transition of the disadvantaged group from being a "group in itself" to being a "group for itself". This is not to say that this transition requires out-group solidarity since, in general, the members of the in-group are, in virtue of their epistemic position, likely to have greater insight into the character and forms of the injustice to which they are subject; it is only to say that the first responsibility of out-group solidarity is to support this transition by providing resources that enable it. Notice, further, that the transition of the in-group as it builds symmetrical relations of solidarity between its members to being a "group for itself" also gives determinacy to the form required of out-group solidarity, that is, what members of the contrastive privileged group are being called to stand in solidarity with, how they are being asked to acknowledge and repay their structural debt.

This brings us to the second respect in which the initial formulation of how to address the political dilemma was too simple, and for which the relationship of the two types of solidarity is crucial, namely, that individuals within a structural group may occupy different positions relative to intersections with other structural groups such that they have responsibilities to stand in relations of solidarity with (out-group solidarity) and solidarity between (in-group solidarity) others within that group. I take this to be one upshot of Nuti's helpful articulation of the idea of 'structural standing' as a relationship between advantaged and disadvantaged structural groups that can also apply within a wider structural group (2019: 192-4). Take the example of women. At its most general, this identifies a structural group 'women*' who are disadvantaged relative to another structural group 'men*' and in which members of the group 'women*' have responsibilities of solidarity towards each other (in-group solidarity) and in which 'men*' have obligations of solidarity towards 'women*' as a structural group (out-group solidarity) not least as one key dimension of discharging their structural debt towards women. At the same time, however, there are many 'women*' who are also members of the structural groups 'Women of Color', 'LGBTQ women', 'Women with disabilities', etc., who have specific solidarity-between responsibilities towards each other-in-(sub)group solidarity-and towards whom women who are not members of the relevant structural group have solidarity-with responsibilities - out-(sub)group solidarity-that are nested within the wider in-group solidarity responsibilities of women as a general group. This feature of social movements such as feminism that aim to be the self-conscious agency of a structural group, to represent that group as a "group-for-itself', points to the responsibility of women who stand in positions of structural privilege with respect to other women along some dimension of privilege/disadvantage being willing to defer (within limits of justice) to the specific goals set by members of structural group in question. But it also points to the responsibility of the relevant sub-group of women being willing 
to articulate these goals in ways that mesh with the articulation of the wider goals of women as a general structural group and through this with the particular goals of other sub-groups who similarly engage in such articulation of meshing goals. This "dialectics" of solidarity - expressed in ethical concepts such as 'sisterhood' - mediates the relationship of general and particular interests and, to the extent that the relevant responsibilities of solidarity are acknowledged and acted on, disarms the potential for a toxic factionalism that may threaten to undo the movement as a whole. (It may be salient to note here that the potential for such a toxic factionalism to emerge are perhaps greatest when they concern whether or not a given 'sub-group' are or are not members of the structural group 'women*'. The character of current public disputes concerning the status of trans-women as 'women*' may be taken as an illustration of this point.)

This last point helps to account for the importance of ethos in social movements, of the cultivation of an ethical culture of mutual responsiveness that is attuned to diverse structural standings within the group 'women*' against the backdrop of a general in-group solidarity relation grounded in the structural disadvantage of women as a group in society. It is important because 'responsibilities' of solidarity are such that they cannot be fully specified in terms of determinate obligations but require a dispositional relation to the other in and though which their responsibility is worked out in an ongoing and mutual supportive process. One way to clarify this point is through Rosen's (2012) distinction between 'respect as observance' and 'respect as respectfulness'. The former refers to a mode of relation to the other in which one recognizes the dignity of their person. One does not, for example, breach their rights. The latter refers to a mode of relation to the other in which I recognize the dignity in her person. I do not, for example, humiliate her. Solidarity requires not only that one relate to the dignity of the person of other members of the structural group (respect as observance), but also that 'we' need to relate to each other in ways that acknowledge the dignity in our persons through mutually respectful forms of communication and conduct (respect as respectfulness). This mode of relationship is not required merely as an instrumentally valuable means for achieving the goals of solidarity, rather it is a constitutive part of solidarity, of standing in a relationship of solidarity to others. This is the point that links the concept of solidarity and its expression through notions such as sisterhood or comradeship to the idea of friendship and, hence, to the centrality of ethos.

The discussion of intersectionality directs us to a further important point about feminism as the movement through which women as a structural group self-consciously articulate their critique of historical-structural injustice and propose ways of overcoming it, namely, that it is necessarily also connected to all those other disadvantaged structural groups that have women in their membership and the realization of its goals are linked to the realization of the goals of these other movements. These movements as collective agents thus also have responsibilities of solidarity to each other grounded in the co-dependence of their goals. So I noted above that, for example, white women who stand in a specific relation of privilege to 'Women of Colour' have a responsibility to support and defer to the specific goals of 'Women of Colour' in relation to the intersection of gendered and racialised social structures, but also that 'Women of Colour' have a responsibility to set goals that mesh with the articulation of the wider goals of women as a general structural group and through this with the particular goals of other sub-groups who similarly engage in such articulation of meshing goals. But 'Women of Colour' are also a sub-group of 'People of Colour' as a disadvantaged structural group formed through the racialised structures of society and hence the same considerations apply in that context. It then matters that the goals of the two general structural groups - 'women*' and 'people of colour*' - are compatible (and can mesh in this weak sense) and this point to a further important role for intersectional sub-groups such as 'Women of Colour', namely, 
that in setting their own goals, they are also mediating between the movements representing 'women*' as a structural group and 'people of colour*' as a structural group and acting as a channel of communication and coordination between them. The requirement of responsiveness is not simply of instrumental value, as I have noted, but it does have significant instrumental value because in being responsive to 'Women of Colour', the wider movements are also responsive to each other and recognize each other as having responsibilities to ensure that the pursuit of their goals can mesh with each other.

Nuti's emphasis on an inclusive participatory approach to redressing historical-structural injustice may be seen as an implicit expression of this point. But it also matters for an issue that she raises concerning a possible tension between backwards-looking reparations for past injustice and forward-looking redress for current injustice, namely, that the form of reparations will be both constrained and directed by the responsibilities of solidarity that the historicalstructural group in question has to the other structural groups with which it is interconnected. If, as Nuti notes, it is the case that, for example, 'the content of many demands for reparations advanced by BLM ... resonates with distributive and structural injustice suffered by African Americans', this may also be an acknowledgment of their solidarity with other structurally disadvantaged groups such as women that have African American members.

What I have tried to argue in drawing attention to the significance of the complementarity of the two accounts of solidarity is that implicit within Nuti's account are some resources for recognizing that the concept of solidarity should be central to theorizing redress for structural injustice and that appropriately developed and supplemented by an account of soldiarity, as I have tried to do in this section, this offers a way of responding to the political dilemma with which I began. Solidarity - and more specifically the dialectic of (symmetrical) in-group solidarity and (asymmetrical) out-group solidarity - provides the missing link that enables us to negotiate the problem that justly addressing structural injustice requires that responsibility for change is located primarily with those who are structurally privileged on the relevant dimension(s) and yet that the decision-making power for the direction of change should be attributed primarily to those structurally disadvantaged.

\section{Conclusion}

In this essay I have sought to situate Nuti's discussions of structural injustice and historical injustice within the context of a political dilemma that confronted Young's own discussion of structural injustice and which her early death meant she did not address. The dilemma emerges from a paradox that can be stated simply: justly addressing structural injustice would require that those subject to structural injustice enjoy the kind of privileged position of decision-making power that their being subject to structural injustice denies them. The dilemma thus concerns how to justly address structural injustice. I have argued that although Nuti's argument falls short of providing an fully theorized account of how to negotiate this dilemma, we can draw out features that are implicit within her account to engage with contemporary debates on political solidarity in ways that lead to a more fully theorized account. In particular, I argue that Nuti's arguments provide some of the resources and certainly the site for seeing the 'competing' symmetry and asymmetry accounts of political solidarity as complementary and drawing attention to the different relations of in-group solidarity and out-group solidarity (solidarity between and solidarity with) that are appropriate to different kinds of structural relationships. The resulting dialectic of solidarity provides a way of theorizing Nuti's focus on inclusive participatory forms of redress that can negotiate the political dilemma. 
Acknowledgements I am grateful to Jennifer Page for the invitation to contribute to this symposium and to Alasia Nuti for providing the occasion. I am also grateful to two referees for their helpful suggestions.

Not Applicable

Open Access This article is licensed under a Creative Commons Attribution 4.0 International License, which permits use, sharing, adaptation, distribution and reproduction in any medium or format, as long as you give appropriate credit to the original author(s) and the source, provide a link to the Creative Commons licence, and indicate if changes were made. The images or other third party material in this article are included in the article's Creative Commons licence, unless indicated otherwise in a credit line to the material. If material is not included in the article's Creative Commons licence and your intended use is not permitted by statutory regulation or exceeds the permitted use, you will need to obtain permission directly from the copyright holder. To view a copy of this licence, visit http://creativecommons.org/licenses/by/4.0/.

\section{References}

Kolers A (2016) A moral theory of solidarity. Oxford University Press, Oxford

Nuti A (2018) Temporary labour migration within the EU as structural injustice. Ethics Int Aff 32(2):203-225

Nuti A (2019) Injustice and the reproduction of history: Structural inequalities, gender and redress. Cambridge University Press, Cambridge

Owen D (2014) Responsibilities of Justice. In: Niesen P (ed) Gerechtigkeit, Demokratie, Inklusion. Motive aus dem Werk von Iris Young, Nomos, pp 93-110

Rawls J (1993) Political Liberalism. Columbia University Press, New York

Rosen M (2012) Dignity. Harvard University Press, Cambridge

Sangiovanni A (2015) Solidarity as joint action. J Appl Philos. https://doi.org/10.1111/japp.12130

Scholz S (2015) Seeking solidarity. Philos Compass 10(10):725-735

Scholz S (2008) Political solidarity. Penn State University Press, Pennsylvania

Young IM (2006) Taking the basic structure seriously. Perspect Polit 4(1):91-97

Young IM (2007) Global challenges. Polity Press, Cambridge

Publisher's Note Springer Nature remains neutral with regard to jurisdictional claims in published maps and institutional affiliations. 